\title{
Enhancing Stream Sediment Geochemical Anomalies Using Spatial Imaging: Case Study from Dagbala and Its Environs
}

\author{
Adiotomre, E. E. \\ Department of Geology, Delta State University, Abraka, P. M. B. 1, Abraka, Delta State, Nigeria.
}

\begin{abstract}
The exploration for solid minerals is a very demanding and costly operation and exploration techniques are continually modified, with the better data interpretation approach continuously sought after by operators of the solid mineral industry, so as to improve the success rate of mineral deposit discovery. Spatial imaging approach to interpretation of anomalies related to stream sediment geochemical data is increasingly being recognized, as a significant component of the geochemical survey data analysis in the prospect for concealed mineral deposits. It is apparent that the spatial rendering of such data enhances the interpretation of associated anomalies. The present study, therefore, adopts this technique to investigate the regional distribution of five chemical elements $(A u, Z n, P b, C u$, and $A g)$ in stream sediments derived predominantly from Precambrian Basement rocks in the Dagbala area. Stream sediment samples were analyzed for these elements in bulk fractions with an Atomic Absorption Spectrophotometer after hot extraction with aqua regia. In order to improve the spatial mapping of geochemical anomalies, the computed statistical threshold for the chemical data is used to augment geochemical models developed with Surfer - a contouring and 3-D surface mapping package. Stream sediment concentration data are extrapolated or interpolated at the sample points on stream beds, allowing geochemical anomalies to be aptly extracted for optimal spatial assessment. Geochemical models show anomalies of $\mathrm{Ag}, \mathrm{Cu}, \mathrm{Au}$, and $\mathrm{Zn}$, while grid vector maps depict the dispersion trend of the elements studied.
\end{abstract}

Keywords: Dagbala; Geochemical Anomaly; Dispersion trend; Mineralization; Nigeria Basement Complex; Surfer

\section{Introduction}

The geological processes that result in the formation and deposition of mineral deposits may cause the deposits to localize at or near the earth's surface (Mukherjee et al., 2007). The processes are both physical and chemical and generally result in the development of diagnostic signatures (textural, mineralogical, geophysical or geochemical) as the mineral deposit is formed (Xie and Yin, 1993; Mukherjee et al., 2007). The associated signatures are commonly sought after using geologic medium such as stream sediments, soil and rocks in the prospect for concealed mineral deposits or in resource management and environmental studies (Fletcher, 1997; Mukherjee et al., 2007; Alexakis, 2008). Stream sediment geochemical prospecting technique is commonly adopted where there is a good concentration of rivers in the area delimited by the survey (Webb and Thompson, 1977; Mikoshiba et al., 2006; Mukherjee et al., 2007). Termite mounds have also been used as a geochemical sampling medium to augment conventional soil geochemical surveys when thick regolith and transported cover exist (Stewart et al., 2012; Arhin and Nude, 2010). Whatever geochemical medium is preferred, the ultimate goal is to determine the spatial patterns in the distribution of the elements, specifically those abnormal patterns or geochemical anomalies related to mineralization (Webb and Thompson, 1977). The use of stream sediment geochemical survey in the search for mineral deposits is based on the premise; those sediments contain elements that are mobilized by weathering from adjacent watersheds into stream beds. Consequently, the chemistry of the sediments is representative of the composition of the drainage basin (Webb and Thompson, 1977; Mikoshiba et al., 2006; Mukherjee et al., 2007).

Secondary negative and positive anomalies exist in stream sediments and are both useful in the prospect for ore deposits (Suslov, 1992; Shi and Wang, 1995). The anomalies may co-exist or occur singly in the low background or high background area; the joint occurrence of both anomalies in stream sediments has been interpreted to suggest the dominance of lateral dispersion in element concentration (Shi and Wang, 1995). The occurrence of negative anomalies on the margin of positive anomalies in the low background and high background areas has been reported to indicate concentration and depletion in element content occurring to a different extent in both areas during lateral dispersion (Shi and Wang, 1995). The situation where negative anomalies occur around positive anomalies only in the low background area has also been documented. This pattern would develop when high level of element's concentration occurs as elements are dispersed from a negatively anomalous region to a positively anomalous region (Shi and Wang, 1995).

Previous studies have suggested the potential for the mineralization of Au and associated elements in the study area (Adepoju and Adekoya, 2011, 2012). These studies, and several other studies conducted in 
different geologic settings (e. g. Reid, 1993; Adekeye, 1999; Atsuyuki et al., 2005; Alexakis, 2008; Bamigboye and Adekeye, 2011) used stream sediment sampling as a medium to prospect for geochemical element. In addition, these workers, developed geochemical distribution maps of element concentration, in river beds and their tributaries. Since stream sediment concentration data are collected by following rivers where they occur, the data obtained from stream sediment survey are more or less point data with irregular sample locations and non-uniform sampling density (e.g. Nugraha, 2011). Nevertheless, the majority of stream sediment geochemical studies are based on a conventional method of interpretation, where results of geochemical survey are presented as point data in geochemical maps. This conventional practice of delineating anomaly based on point data on the stream bed provides limited information on the spatial distribution of element concentration. However, it is emphasized in past studies, that the spatial variation of anomalous concentration will be effectively established over an area when point data on stream beds are extrapolated or interpolated beyond the sample point. In as much as chemical elements represented in stream sediments are presupposed to have mobilized from adjoining watersheds (e.g. Mikoshiba et al., 2006; Mukherjee et al., 2007). Although the spatial analyses of geochemical concentration data have been used in the past for improved interpretation of anomalous elements (e.g. McClenaghan et al., 1997; Adams, 2006; Mukherjee et al., 2007; Bamigboye and Adekeye, 2011; Samal et al., 2011), the use of interpolated or extrapolated geochemical spatial variation maps continues to be scarce. In the present study, stream sediment concentration data are analyzed by interpolating or extrapolating point data spatially around sampling points. This allows the creation of spatial geochemical models that are used for the optimal assessment of the spatial distribution of observed anomalies, and also provide adequate visualization of element dispersion trends in the study area.

\section{Geologic Setting}

The study area is situated within the south-western Basement Complex of Nigeria, and it is delimited by latitude $7 \mathrm{o} 19^{\wedge} \mathrm{N}$ and $7 \mathrm{o} 23^{\top} \mathrm{N}$, and longitude 6o $14^{`} \mathrm{E}$ and 6o 19 $\mathrm{E}$ (Fig. 1). The Nigerian Basement Complex forms a part of the Pan-African mobile belt and lies between the West African and Congo Cratons and south of the Tuareg Shield (Oyawoye, 1972; Black, 1980, Wright, 1985). It is intruded by the Mesozoic calc-alkaline ring complexes (Younger Granites) of the Jos Plateau and is unconformably overlain by Cretaceous and younger sediments (Burke and Dewey, 1972; Odeyemi, 1976; Dada, 2006; Obaje, 2009).

The Basement Complex rocks are subdivided into migmatite-gneiss complexes, the older metasediments, the younger metasediments, the older granites and, the younger granite complexes and volcanic rocks (Grant, 1970; Rahaman, 1976; Obaje, 2009, Obiora and Ukaegbu, 2009). The Migmatite-Gneiss Complex is the commonest and the oldest basement rock and comprises of gneisses (biotite gneiss and banded gneiss), amphibolites, migmatite and metavolcanics. It is of sedimentary origin but was later profoundly altered by metamorphic and igneous processes. The older metasediments were also among the earliest rocks to form on the Nigerian Basement Complex. Similar to the Migmatite-Gneiss Complex, they are also of sedimentary origin before they underwent prolonged and repeated metamorphism; and include rocks such as quartzite, calcareous rocks (e.g. marble) and relics of highly altered clayey sediments and igneous rocks. The Younger Metasediments consists of belts of roughly north-south trending, slightly metamorphosed ancient Precambrian sedimentary and volcanic rocks that underlain most parts of the Basement Complex. The major rocks in this category are quartz-biotite-muscovite schist and coarse-grained feldspar-bearing micaceous schists, although ferruginous quartzites and talc schists may also occur. The older granites are widespread throughout the Basement Complex and occur as large circular masses within the Schists and the Migmatite-Gneiss Complexes. The Younger Granite Complexes in Nigeria are found mainly on the Jos Plateau, forming a distinctive group of intrusive and volcanic rocks that are bounded by ring dykes or ring faults.

The local geology of the study area is dominated by the metasediments considered by Odeyemi (1988) to be part of the Igarra Schist Belt that overlies the Migmatite-Gneiss Complex. The main rock types that occur in the study area include quartz-biotite schist, porphyritic granite and granite gneiss (Fig. 2).

\section{Materials And Methods}

The initial part of the study entails a reconnaissance geochemical stream sediment survey, in which 100 samples of stream sediment weighing approximately $350 \mathrm{~g}$ each are collected from depths of $15-20 \mathrm{~cm}$ along river beds over an area of $224 \mathrm{~km}^{2}$. Precaution was taken to sample recently transported sediments, and care was taken also to avoid materials derived from collapsing banks. Samples were oven dried and disaggregated before they were screened through a $<177 \mu \mathrm{m}$ stainless steel sieve. $0.25 \mathrm{~g}$ weights of samples passing $177 \mu \mathrm{m}$ are weighed in borosilicate test tubes and subjected to hot aqua regia digestion before they were analyzed for $\mathrm{Au}$, $\mathrm{Ag}, \mathrm{Pb}, \mathrm{Zn}$ and $\mathrm{Cu}$ content with an Atomic Absorption Spectrophotometer. The resulting chemical data were processed with Surfer, which is a 3-D surface mapping, contouring and gridding package provided by Golden Software Incorporation. 
For use in Surfer, the concentration data are transformed into XYZ format to generate a data file in Microsoft Office Excel. In order to generate the data file, the study area is subdivided into equal blocks patterned as rows and columns (Fig 3). The concentration data and sample locations are georeferenced with respect to the geographic coordinates of the rows and columns. The intersection of each row and column constitutes a grid node, and each row contains grid nodes with the same Y coordinate while each column contains grid nodes with the same X coordinate. In Microsoft Office Excel, the data is organized in columns of $\mathrm{XYZ}$ data points. The first two columns are the $\mathrm{X}$ and $\mathrm{Y}$ coordinates for the data points. The third column is the $\mathrm{Z}$ value or element concentration assigned to the XY point (Surfer search for these coordinates in these columns by default). As part of the data preparation, Latitude and Longitude are presented as decimal degrees for use in Surfer. The data is imported into Surfer and a grid file created with the Kringing algorithm tool. Surfer is used to generate geochemical models that consist of contoured concentration, grid vector and 3-D wireframe maps so as to amply visualize the spatial distribution of concentration data and anomalies in the study area. The wireframe 3-D surface is a three-dimensional rendering of the grid file produced by linking $Z$ values along lines of constant $\mathrm{X}$ and $\mathrm{Y}$, and with a height that corresponds to the element content associated with the grid node. The grid vector map contains element content information and is characterized by arrows that illustrate the changing trend in element spatial concentration. The threshold of analyzed geochemical elements is computed in line with Kock and Link (1971) and used to augment the analysis of spatial maps so that geochemical anomaly is overtly delineated.

\section{Results And Discussion}

The results of the chemical analysis of stream sediment samples from the area of study shows $\mathrm{Au}$ and $\mathrm{Cu}$ are characterised by wide ranges of concentration ( 0.56 to $10.12 \mathrm{ppm}$ and 0.92 to $6.22 \mathrm{ppm}$ respectively). While the concentration ranges of other associated elements are narrow (Ag: 0.01 to $2.25 \mathrm{ppm} ; \mathrm{Zn}: 0.1$ to $4.2 \mathrm{ppm} ; \mathrm{Pb}$ : 0.14 to $2.84 \mathrm{ppm}$ ) (Tables 1 and 2). The mean content of $\mathrm{Au}, \mathrm{Ag}, \mathrm{Cu}, \mathrm{Zn}$ and $\mathrm{Pb}$ are 5.7984, 0.9213, 2.6913, 1.9116 , and $1.5245 \mathrm{ppm}$ respectively (Table 2). The highest Au content $(10.12 \mathrm{ppm}$ ) is recorded in stream sediment in location 15(i.e. L15) while the lowest recorded Au value $(0.56 \mathrm{ppm})$ is associated with stream sediment in location 6(L6). Ag content in analysed sediments reach a maximum value of $2.25 \mathrm{ppm}$ at location 1(L1), and the minimum Ag content of 0.01ppm is recorded in sediment sampled from location 6 (L6) (Table 1). The maximum $\mathrm{Cu}$ content of 6.22ppm is recorded from the analysis of the sediment sample located at L15 while a minimum $\mathrm{Cu}$ content of $0.92 \mathrm{ppm}$ is associated with sample collected in location 28(L28) (Table 1). Maximum (4.2ppm, 2.84ppm) and minimum (0.1ppm, 0.14ppm) $\mathrm{Zn}$ and $\mathrm{Pb}$ contents occur in locations $17(\mathrm{~L} 17)$ and 25(L25) and locations 6(L6) and 12(L12) respectively (Table 1).

Generated spatial geochemical models illustrate element concentration ranges designated as high background and low background areas based on average background value, and anomalies of $\mathrm{Au}, \mathrm{Ag}, \mathrm{Cu}$ and $\mathrm{Zn}$ and (Figs. 4a-4d). Computed statistical metrics of element content in sediment samples indicate that the threshold value that separates background from Au anomalies is $11.161 \mathrm{ppm}$ (Table 2), which is $1.041 \mathrm{ppm}$ higher than the maximum recorded Au content of the sediments analysed. However, the spatial rendering of the concentration data depicts closed elliptical-spherical contours northwards of Dagbala in the area around InemeOsa (Fig. 4a) which suggest the occurrence of a positive Au anomaly. The pattern of the concentration contours illustrates a southwest spatial decrease in $\mathrm{Au}$ content from the anomaly in the northeast through the low background area in the southwest (Fig. 4a).

The threshold value (2.4973ppm; Tables 1 and 2) for discriminating background from anomalies is $0.2473 \mathrm{ppm}$ higher than the maximum Ag content (2.25ppm; Tables 1 and 2) in the stream sediments, which suggest an absence of anomalous concentration of Ag in the study area. On the contrary, the analysis of spatial concentration map shows semi-concentric contours characterised by an inward increase in Ag content in the eastern part of Dagbala and Ineme-Osa, which exemplify the western part of a positive Ag anomaly that developed to the east of these localities (Fig. 4b). The configuration of the contours is characterised by a spatial decrease in Ag content to the west of the anomaly and through the high background to the low background area in the western segment of the study area. An apparent change from low background to high background occurs at approximately 10 kilometres northwest of Dagbala typifies by semi-concentric contours that abut the northwestern margin of the study area (Fig. 4b). This suggests that a positive Ag anomaly also developed northwesterly of the study area.

The maximum $\mathrm{Cu}$ content (6.22ppm; Tables 1 and 2) recorded in the analysed stream sediments is, higher than the computed statistical threshold value (5.1497ppm; Tables 1 and 2) used for discriminating background from $\mathrm{Cu}$ anomalies in the study area, suggesting copper anomalous concentration. The contours obtained in the spatial rendering of the concentration data are concentric in form in Ineme-Osa and north of Dagbala (Fig. 4c). The observed configuration of these contours is characterised by an inward increase in $\mathrm{Cu}$ content which may illustrate a positive $\mathrm{Cu}$ anomaly. At approximately $7 \mathrm{~km}$ northwards of Ojirami-Ogbo, concentration contours show an inward increase in $\mathrm{Cu}$ content and abut the north margin of the study area (Fig. 4c). However, the 
element concentration in this locality did not develop strong geochemical response to illustrate a positive $\mathrm{Cu}$ anomaly. The spatial concentration map also shows elliptical concentration contours situated in a low background area and at approximately four kilometres to the east of Dagbala (Fig. 4c). The configuration of the contours is characterised by an inward decrease in $\mathrm{Cu}$ content which exemplifies a negative $\mathrm{Cu}$ anomaly in this region. An additional negative $\mathrm{Cu}$ anomaly developed approximately $6 \mathrm{~km}$ northwest of Ineme-Osa, although the geochemical response is not as strong as the previous one (Fig. 4c). In this study, negative $\mathrm{Cu}$ anomaly occurs in the low background area while positive $\mathrm{Cu}$ anomaly occurs in the high background area. This is an indication that both depletion and concentration of geochemical element occurred and that lateral migration is an important aspect of the metal concentration process. Similar observations have been reported in the Jungger and Kunlun area of China where negative and positive anomalies occur in stream sediments, in a low background or high background areas (Shi and Wang (1995).

The threshold value $(4.0334 \mathrm{ppm}$ ) used for discriminating background from $\mathrm{Zn}$ anomalies is $0.1666 \mathrm{ppm}$ lower than the maximum $\mathrm{Zn}$ content in the analysed stream sediments, suggesting an anomalous concentration of $\mathrm{Zn}$ in the sediments (Tables 1 and 2). Analysis of the spatially rendered element concentration map reveal sections of semi-circular concentration contours located approximately two kilometres northwards of Ineme-Osa in the north-eastern segment of the study area (Fig. 4d). The pattern of the contours is marked by an inward increase in $\mathrm{Zn}$ content and may illustrate a positive $\mathrm{Zn}$ anomaly in this region.

The maximum $\mathrm{Pb}$ content $(2.84 \mathrm{ppm})$ in the analysed stream sediments is 0.195 lower than the threshold values $(3.035 \mathrm{ppm})$ used for separating background from anomaly in the study area, which suggests an unmineralised concentration of $\mathrm{Pb}$ in the analysed stream sediments (Tables 1 and 2). The analysis of spatial concentration map shows that closed concentration contours are not developed in the high background areas; which also suggest an absence of $\mathrm{Pb}$ related anomaly. Although, semi-circular contours that abut the northern part of the study area are developed approximately $6 \mathrm{~km}$ northwards of Ojirami-Ogbo, the pattern of the contours, however, did not illustrate detail geochemical response to suggest a positive $\mathrm{Pb}$ anomaly (Fig. 4e). In the southern part of the study area, elliptical concentration contours occur in the low background area approximately four and seven kilometres from Ojirami-Ogbo and Dagbala respectively (Fig. 4e). The concentration contours are marked by an inward decrease in $\mathrm{Pb}$ content and have a configuration that illustrates a negative $\mathrm{Pb}$ anomaly. As earlier indicated for $\mathrm{Cu}$, the recognition of a negative $\mathrm{Pb}$ anomaly in the low background area may suggest that ample depletion in metal content occurred during lateral dispersion of element to develop the observed geochemical response.

In 3-D, variation in the height of the surface of the wireframe map is analogous to variations in metal content which decreases to the northwest for $\mathrm{Au}, \mathrm{Ag}$ and $\mathrm{Zn}$ (Figs. 5a-5e). However a different pattern is obtained for wireframe maps illustrating the surface variation in $\mathrm{Cu}$ and $\mathrm{Pb}$ content in the analysed sediments that reveals a general decrease westward and northwards respectively (Figs. 5a-5e). The pronounced local dips in the 3-D wireframe maps for $\mathrm{Cu}$ and $\mathrm{Pb}$ indicate areas of local depletions in metal content during lateral dispersion, which are interpreted as negative anomalies in rendered spatial concentration contour maps.

The dispersion trends of the elements analysed in the sediments is illustrated with a grid vector map superimposed on filled contour maps (Figs. 6a-6e). The trends predicted by the grid vector maps correspond with the spatial variation in metal content interpreted from the concentration contour and 3-D wireframe maps (Figs. 4a-4e, 5a-5e). Grid vector maps contain vital information on magnitude and direction of point data, and for the interpretation of elevation data the arrows point in the direction of the slope and arrow length increases with the steepness of the slope (Golden Software Incorporation). In this study, geochemical models show that the height at any point on the surface corresponds to the element content associated with the grid node. Therefore, concentration is taken as a proxy for elevation and the differently directed arrows in the grid vector maps are interpreted to indicate the changing trend in element spatial content, and also illustrate element lateral dispersion trends over the area of study. Therefore, the arrows point in the direction of lateral dispersion of geochemical elements from positively anomalous to negatively anomalous area. As portrayed on the grid vector maps superimposed on the filled contoured-concentration maps for the elements analysed, the direction of the vector arrows is primarily controlled by the relative position of the positively anomalous and negatively anomalous areas (Figs. 6a-6e). For instance, the vector arrows on the $\mathrm{Au}, \mathrm{Ag}, \mathrm{Zn}$ and $\mathrm{Cu}$ grid vector maps diverge from the positive anomalies located in the eastern segment of the study area (Figs. 6a and 6c). The vector arrows are also observed to converge in the negative anomalies located to the east and central parts of the grid vector maps for $\mathrm{Cu}$ and $\mathrm{Pb}$ respectively (Figs.6c and 6d). In general, vector arrows diverge in high background areas or where positive anomalies exist, and converge in low background areas or where negative anomalies are developed, for the elements analysed in this study (Figs. 6a-6e).

\section{Conclusion}

The results of the present study show that the discrimination of background data from anomalies based on the analysis of spatially rendered geochemical maps is unequivocal, as compared with the use of statistical 
threshold values. However, the study demonstrates that statistical threshold values do not reliably separate background from anomalies, and indicate the inexistence of anomalies (positive or negative) of some of the elements studied whereas their occurrence is illustrated in the spatial geochemical maps produced. Furthermore, pointing arrows in the grid vector maps produced depict the dispersion trends of the elements studied in four delineated concentration zones namely, positively anomalous zones, high background areas, low background areas and negatively anomalous zones. Vector arrows are observed to diverge from positive anomalies or high background areas, and converge in negative anomalies or low background areas. In this way, the relative position of positive anomalies and negative anomalies is clearly defined. Although Reimann et al. (2005) suggest that the threshold values estimated by methods other than the one used in this study may offer a better way for separating background data from anomalies, the application of spatial concentration maps in stream sediment anomaly interpretation is overwhelming satisfactory. Consequently, computed statistical threshold values are only used in this study to complement the interpretation of spatially rendered geochemical models of element concentration. It is, therefore, suggested that spatially rendered geochemical models, should be incorporated in stream sediments geochemical surveys, in order to enhance the interpretation of the anomalies associated with element concentration during lateral dispersion. Furthermore, adopting this approach in the interpretation of stream sediment geochemical survey data will significantly reduce the overall cost of mineral exploration projects and enhance the degree of certainty in locating mineral deposits.

\section{Acknowledgement}

The author thanks the management of the Delta State University, Abraka for their cooperation in supplying the funding and logistical support to undertake this study that is the Phase I of an exploration research project in Auchi Sheet 266. Thanks are also due to Golden Software Incorporation for providing the software used in the interpretation of element concentration data.

\section{References}

[1]. Adams, D. (2006). Geochemical Sampling and Geostatistics - Notes, Delta Mine Training Center; http://www. dmtcalaska.org/course dev/explogeo/class12/notes12. html (accessed August 10, 2013).

[2]. Adekeye, J. I. D. (1999). Heavy minerals in stream sediments and their relationship to bedrock types and mineralization in Oro Area Southwestern Nigeria. Nigeria Journal of Pure and Applied Science, vol. 14, pp. 906-914.

[3]. Adepoju, M. O. and Adekoya, J. A. (2011). Reconnaissance geochemical study of a part of Igarra schist belt, southwestern Nigeria. Ife Journal of Science, vol. 13, no. 1, pp. 75-92.

[4]. Adepoju, M. O. and Adekoya, J. A. (2012). Distribution and assessment of heavy metals in sediments of the river Orle, southwestern Nigeria. Journal of Sustainable Development and Environmental Protection, vol. 2, no. 1, pp. 78-97.

[5]. Alexakis, D. (2008). Geochemistry of stream sediments as a tool for assessing contamination by Arsenic, Chromium and other toxic elements: East Attica region, Greece. European Water, vol. 21, no. 22: pp.57-72.

[6]. Arhin, E. and Nude, M. P. (2010). Use of termitaria in surficial geochemical surveys: evidence for $>125-\mu \mathrm{m}$ size fractions as the appropriate media for gold exploration in northern Ghana. Geochemistry: Exploration, Environment, Analysis, vol. 10, no. 4, pp. 401-406.

[7]. Atsuyuki, O., Noboru, I., Shigeru, T. and Yoshiko, T. (2005). Influence of surface geology and mineral deposits on the spatial distributions of element concentrations in the stream sediments of Hokkaido Japan. Journal of Geochemical Exploration, vol. 86, 86-103.

[8]. Bamigboye, O. S. 1. and Adekeye, J. I. D. (2011). Stream sediment survey of eruku and its environs, central Nigeria: Implication for exploration. IJRAS, vol. 7, no. 2, pp. 160-172.

[9]. Fletcher, W. K. (1997). Stream Sediment Geochemistry in Today's Exploration World. Exploration Geochemistry Paper 2. In "Proceedings of Exploration 97: Fourth Decennial International Conference on Mineral Exploration" edited by A.G. Gubins, pp. 249-260.

[10]. Golden Software Incorporation Surfer 9.

[11]. Kock, G. S. and Link, R. F. (1971). Statistical analysis of geological data (vol. II). John Wiley and Sons, Inc, New York, pp. 326.

[12]. McClenaghan, M. B., Thorleifson, L. H. and DiLabio, R. N. W. (1997). Till geochemical and indicator mineral methods in mineral exploration; In: Proceedings of Exploration 97: Fourth Decennial International Conference on Mineral Exploration, (ed.) Gubins A G, Prospectors and Developers Association of Canada, pp. 233-248.

[13]. Mikoshiba, U. M., Imai, N., Terashima, S., Tachibana, Y. and Okay, T. (2006). Geochemical mapping in northern Honshu, Japan Applied Geochemistry, vol. 21, pp. 492-514.

[14]. Mukherjee, P. K., Purohit, K. K., Saini, N. K., Khanna, P. P., Rathi. M. S., and Grosz, A. E. (2007). A stream sediment geochemical survey of the Ganga River headwaters in the Garhwal Himalaya. Geochemical Journal, vol. 41, pp. 83-95.

[15]. Nugraha, H. S. (2011). Integration of stream sediment geochemical and airborne gamma-ray data for surficial lithologic mapping using clustering methods. Unpublished Master's thesis, Faculty of Geo-Information Scvience and Earth Observation, University of Twente.

[16]. Obaje, N. G. (2009). Geology and Mineral Resources of Nigeria. Lectures Notes in Earth Sciences, vol. 120, pp. 13-30.

[17]. Obiora, C. and Ukaegbu, V. U. (2009). Petrology and geochemical characteristics of Precambrian granitic basement complex rocks in the southernmost part of North-Central Nigeria. Chinese Journal of Geochemistry, vol., 28, no. 4, pp. 377-385.

[18]. Reid, J. C. (1993). A Geochemical Atlas of North Carolina, USA. Journal of Geochemical Exploration, 4711-4727.

[19]. Reimann, C., Filzmoser, P. and Garrett, R. G. (2005). Background and threshold: critical comparison of methods of determination. Total Environment, vol. 346, nos 1-3, pp. 1-16.

[20]. Samal, R. A., Sengupta, R. R. and Fifarek, H. R. (2011). Modelling spatial anisotropy of gold concentration data using GIS-based interpolated maps and variogram analysis: Implications for structural control of mineralization. Journal Earth System Science, 120, no. 4, pp. 583-593.

[21]. Shi, C. and Wang, C. (1995). Regional geochemical secondary negative anomalies and their significance. Journal of Exploration Geochemistry, vol. 55, pp. 11-23.

[22]. Stewart, A. D., Anand, R. R. and Balkau, J. (2012). Source of anomalous gold concentrations in termite nests, Moolart Well, Western Australia: Implications for exploration. Geochemistry, Exploration, Environment, Analysis, vol. 12, pp. 327-337. 
[23]. Suslov, A. B. (1992). Primary Ni negative haloes - a criterion for blind Cu-Ni orebodies. Geophysics Geochemistry Exploration Abroad, vol. 2, pp. 52-55.

[24]. Webb, J. S. and Thompson, M. (1977). Analytical requirements in exploration geochemistry. Pure and Applied Chemistry, vol. 49, pp. 1507-1518.

[25]. Xie, X. and Yin, B. (1993). Geochemical pattern from local to global. In: F. W. Dickson and L. C. Hsu (Editors). Geochemical Exploration 1991. Journal Geochemical Exploration, vol. 47, pp. 109-129.

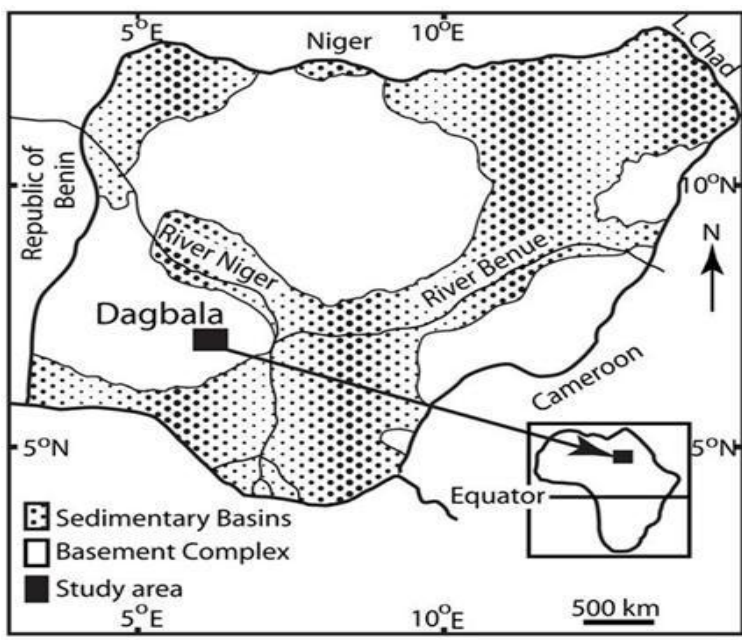

Fig. 1 - Geologic map of Nigeria showing the study area. Inset: Map of Africa.

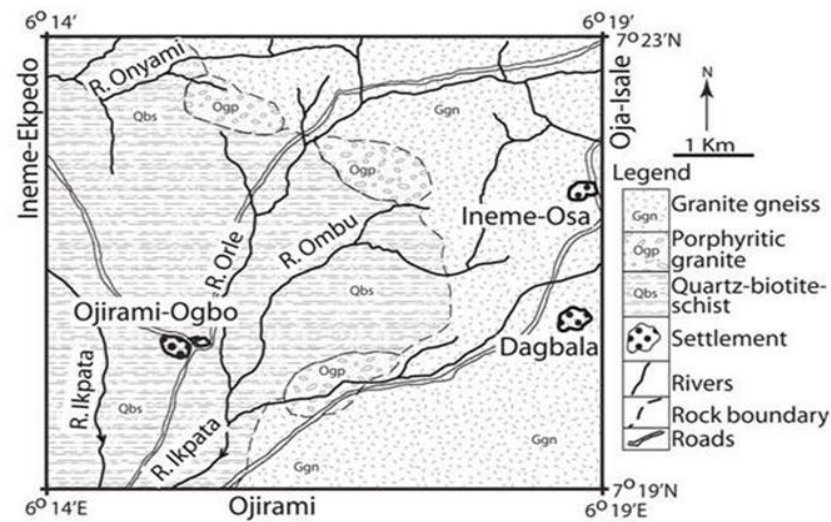

Fig. 1- Schematic geologic map of the study area

$$
X \text { coordinate }
$$

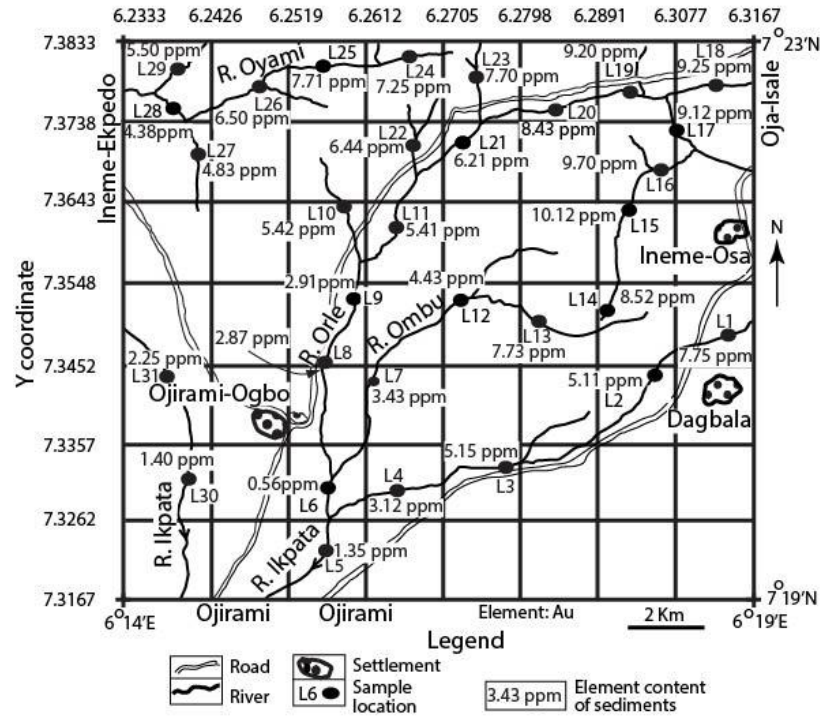

Fig. 3 - Grid map showing location of stream sediment samples.

Table 1 - Stream Sediment Geochemical Data 
Enhancing Stream Sediment Geochemical Anomalies Using Spatial Imaging: ...

\begin{tabular}{|c|c|c|c|c|c|}
\hline \multirow{2}{*}{$\begin{array}{c}\text { Location/Sample } \\
\text { ID }\end{array}$} & \multicolumn{5}{|c|}{ Elements Concentration(ppm) } \\
\cline { 2 - 6 } & $\mathbf{A u}$ & $\mathbf{A g}$ & $\mathbf{C u}$ & $\mathbf{Z n}$ & $\mathbf{P b}$ \\
\hline L1 & 7.75 & 2.25 & 4.7 & 3.28 & 1.17 \\
\hline L2 & 5.11 & 2.22 & 4.1 & 3.15 & 0.34 \\
\hline L3 & 5.15 & 1.56 & 2.56 & 1.1 & 0.67 \\
\hline L4 & 3.12 & 0.9 & 2.44 & 0.7 & 0.36 \\
\hline L5 & 1.35 & 0.3 & 2.57 & 0.4 & 0.48 \\
\hline L6 & 0.56 & 0.01 & 2.9 & 0.1 & 0.45 \\
\hline L7 & 3.43 & 0.7 & 1.82 & 1 & 0.6 \\
\hline L8 & 2.87 & 0.1 & 1.38 & 1.11 & 0.98 \\
\hline L9 & 2.91 & 0.07 & 1.18 & 1.19 & 1.02 \\
\hline L10 & 5.42 & 0.25 & 1.8 & 1.6 & 1.68 \\
\hline L11 & 5.41 & 0.47 & 1.77 & 0.47 & 1.34 \\
\hline L12 & 4.43 & 1.71 & 2.56 & 1.06 & 0.14 \\
\hline L13 & 7.73 & 1.65 & 2.65 & 1.38 & 1.4 \\
\hline L14 & 8.52 & 1.81 & 2.26 & 1.31 & 1.94 \\
\hline L15 & 10.12 & 2.13 & 6.22 & 3.01 & 1.81 \\
\hline L16 & 9.7 & 1.85 & 4.96 & 3.2 & 1.97 \\
\hline L17 & 9.12 & 2.1 & 3.62 & 4.2 & 2.01 \\
\hline L18 & 9.25 & 1.9 & 3.87 & 3.9 & 2.12 \\
\hline L19 & 9.2 & 1.57 & 4.01 & 3.2 & 2.12 \\
\hline L20 & 8.43 & 1.1 & 3.4 & 2.5 & 2.03 \\
\hline L21 & 6.21 & 0.11 & 1.5 & 1.65 & 1.75 \\
\hline L22 & 6.44 & 0.15 & 1.77 & 1.71 & 1.8 \\
\hline L23 & 7.7 & 0.48 & 2.58 & 2.23 & 2.2 \\
\hline L24 & 7.25 & 0.24 & 2.57 & 2.2 & 2.3 \\
\hline L25 & 7.71 & 0.16 & 3.71 & 2.36 & 2.84 \\
\hline L26 & 6.5 & 0.3 & 2.8 & 2.23 & 2.53 \\
\hline L27 & 4.83 & 0.5 & 1.7 & 2.15 & 2.15 \\
\hline L28 & 4.38 & 1.03 & 0.92 & 2.48 & 2.32 \\
\hline L29 & 5.5 & 0.68 & 1.8 & 2.42 & 2.47 \\
\hline L30 & 1.4 & 0.08 & 1.83 & 0.75 & 0.97 \\
\hline L31 & 2.25 & 0.18 & 1.48 & 1.22 & 1.3 \\
\hline
\end{tabular}

Table 2 - Descriptive Statistics of Stream Sediment Geochemical Data

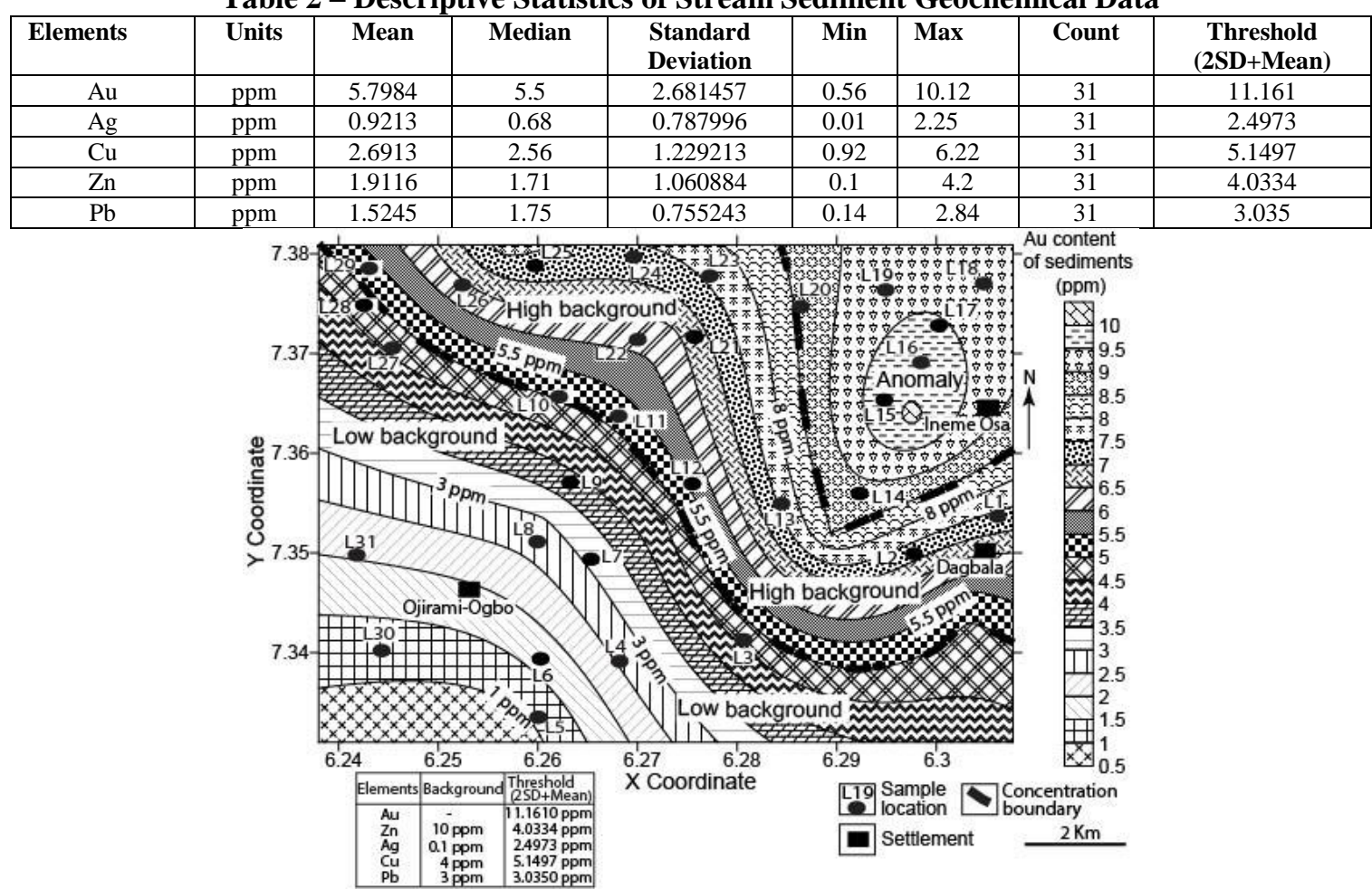

Fig. 4a - Concentration contour map of Au distribution. Inset: Background of some elements in normal mineralized soils (Hawkes and Webb, 1962) and computed element threshold. 


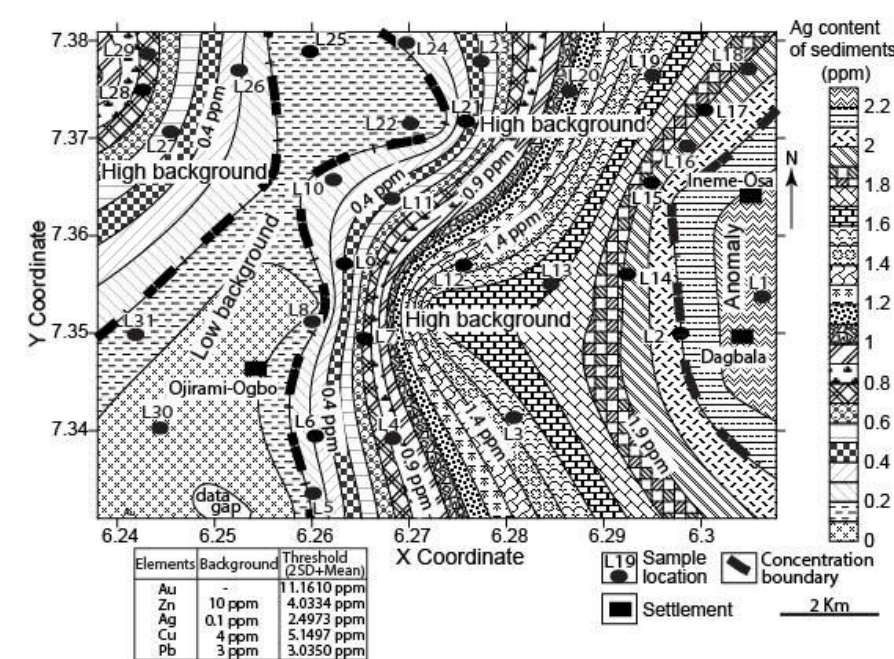

Fig. 4b - Concentration contoured map of Ag distribution. Inset: Background of some elements in normal mineralized soils (Hawkes and Webb, 1962) and computed element threshold.

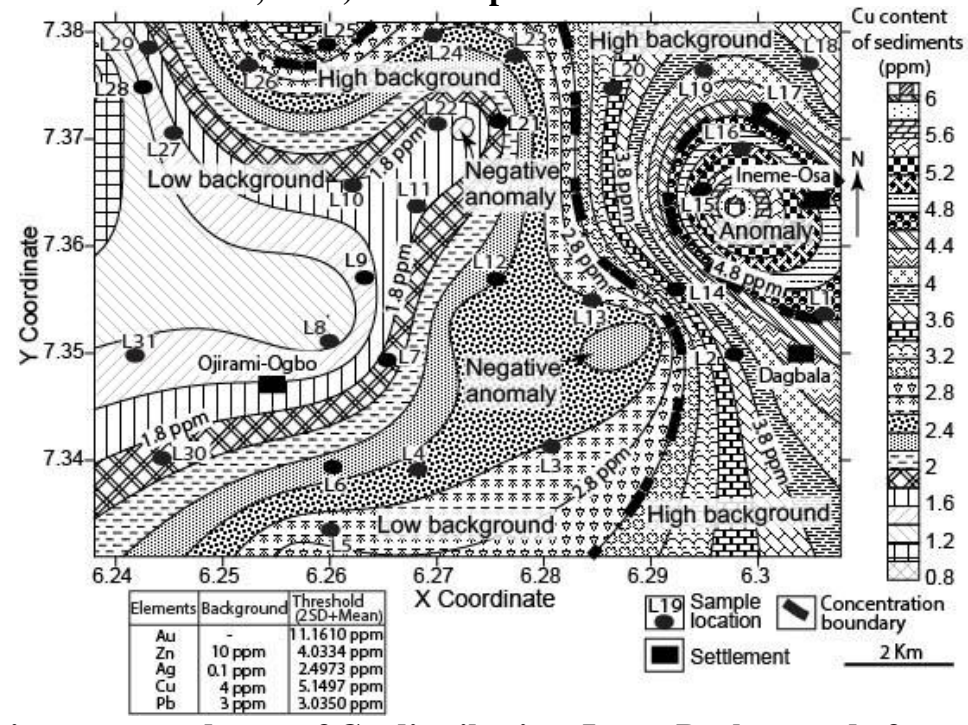

Fig. 4c - Concentration contoured map of $\mathrm{Cu}$ distribution. Inset: Background of some elements in normal mineralized soils (Hawkes and Webb, 1962) and computed element threshold.

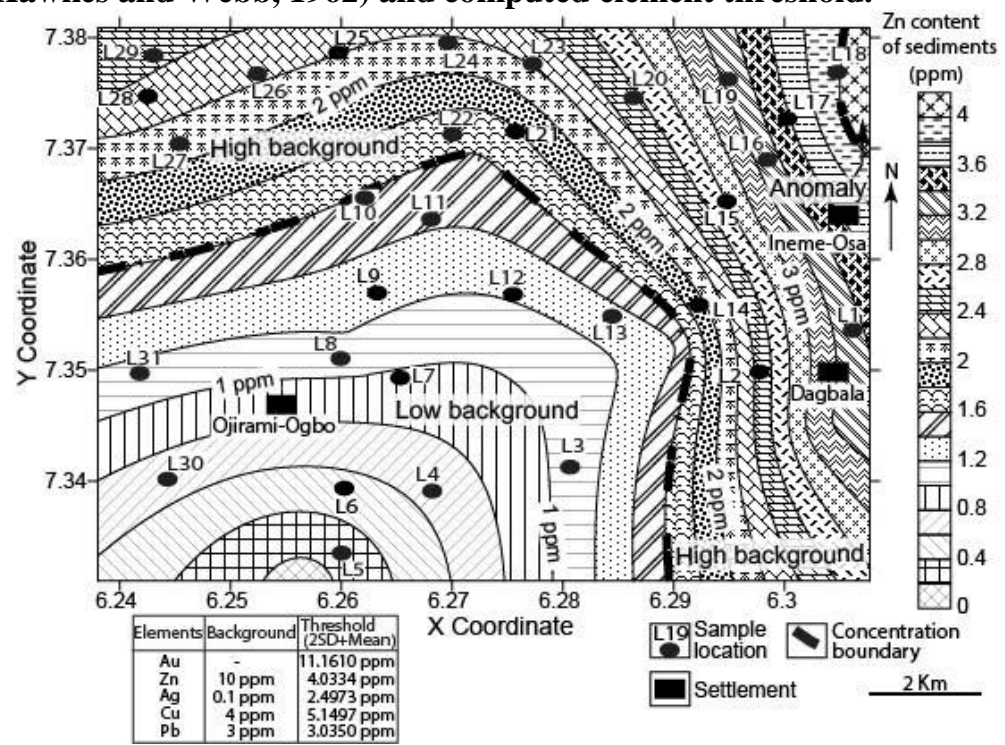

Fig. 4d - Concentration contoured map of $\mathrm{Zn}$ distribution (inset: Background of some elements in normal mineralized soils, after Hawkes and Webb (1962) and computed element threshold). 


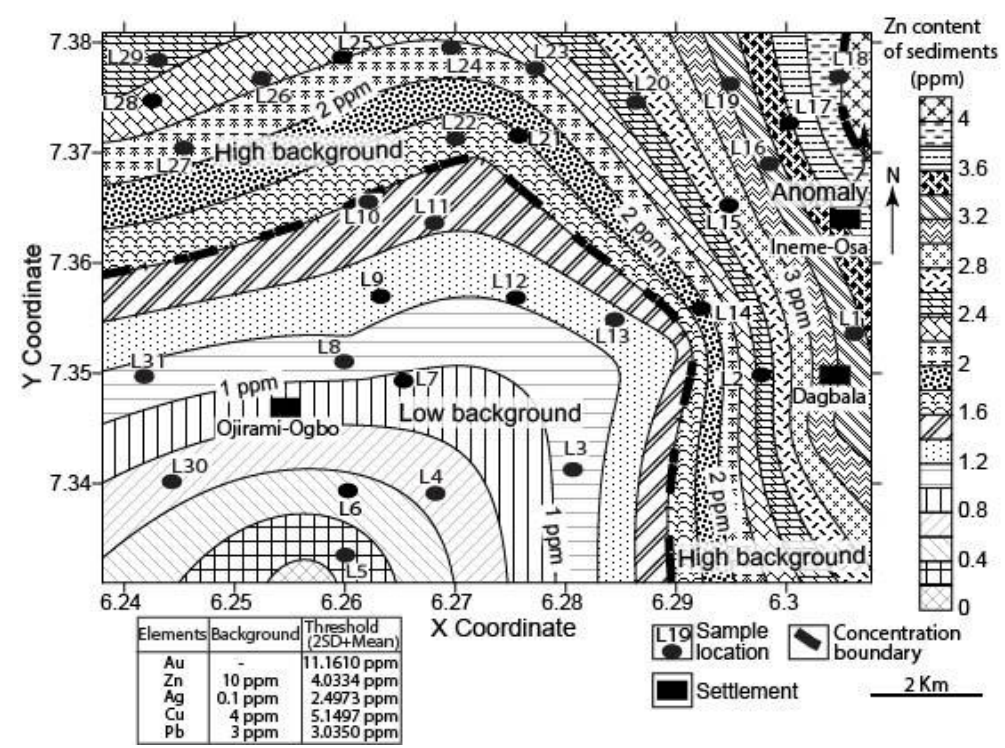

Fig. 4e - Concentration contoured map of $\mathrm{Pb}$ distribution. Inset: Background of some elements in normal mineralized soils (Hawkes and Webb, 1962) and computed element threshold.

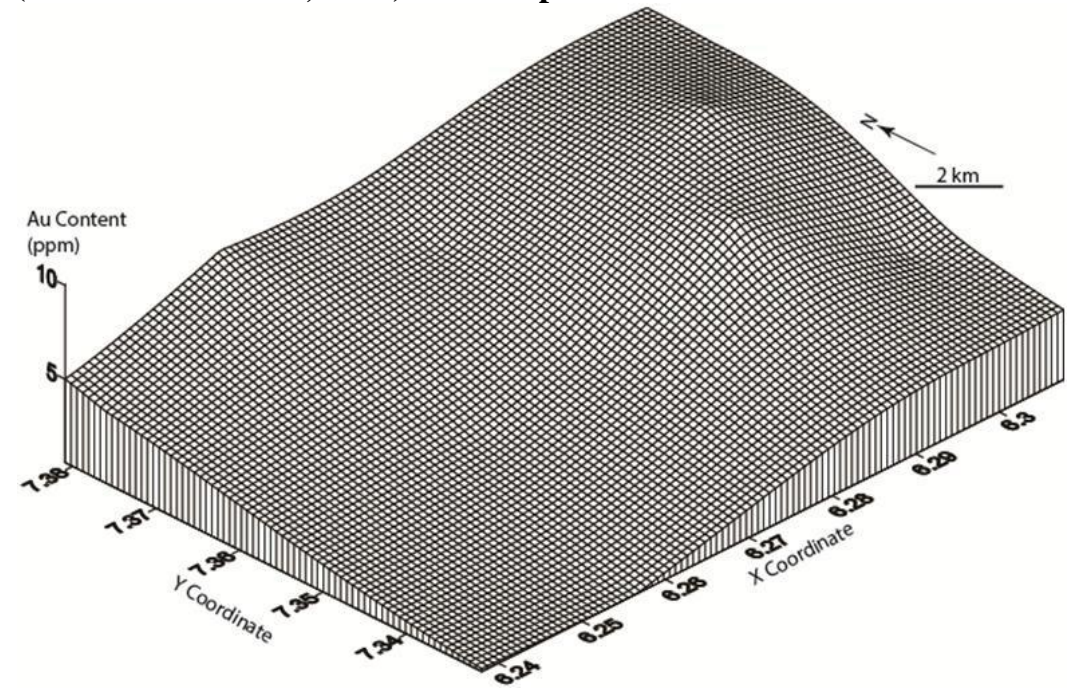

Fig. 5a - 3-D Wireframe map showing the surface variation of Au content in stream sediments. The height of the surface illustrates a general metal content that decreases to the northwest.

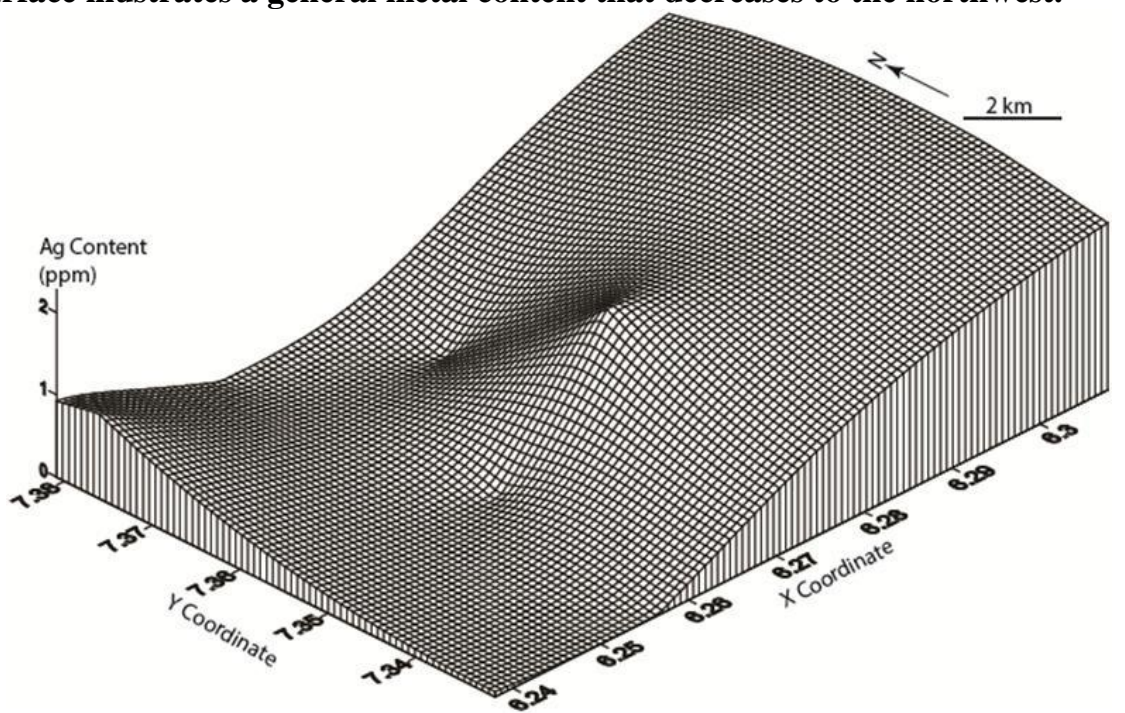

Fig. 5b - 3-D Wireframe map showing the surface variation of Ag content in stream sediments. The height of the surface illustrates a general metal content that decreases to the northwest. 


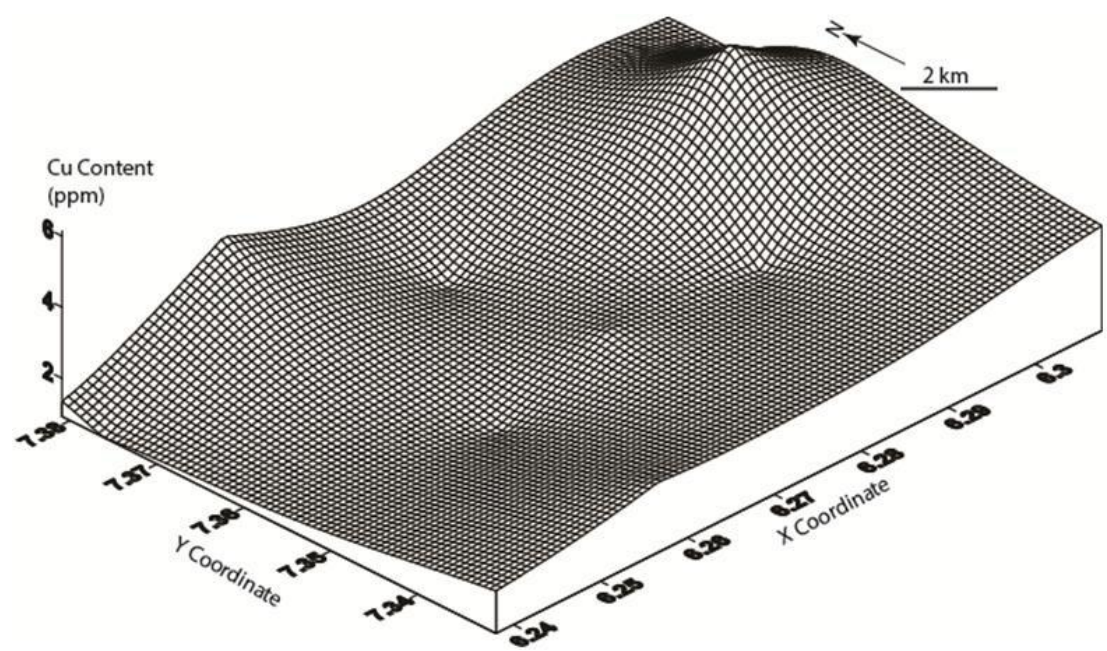

Fig. 5c - 3-D Wireframe map showing the surface variation of $\mathrm{Cu}$ content in stream sediments. The height of the surface illustrates a general metal content that decreases to the west.

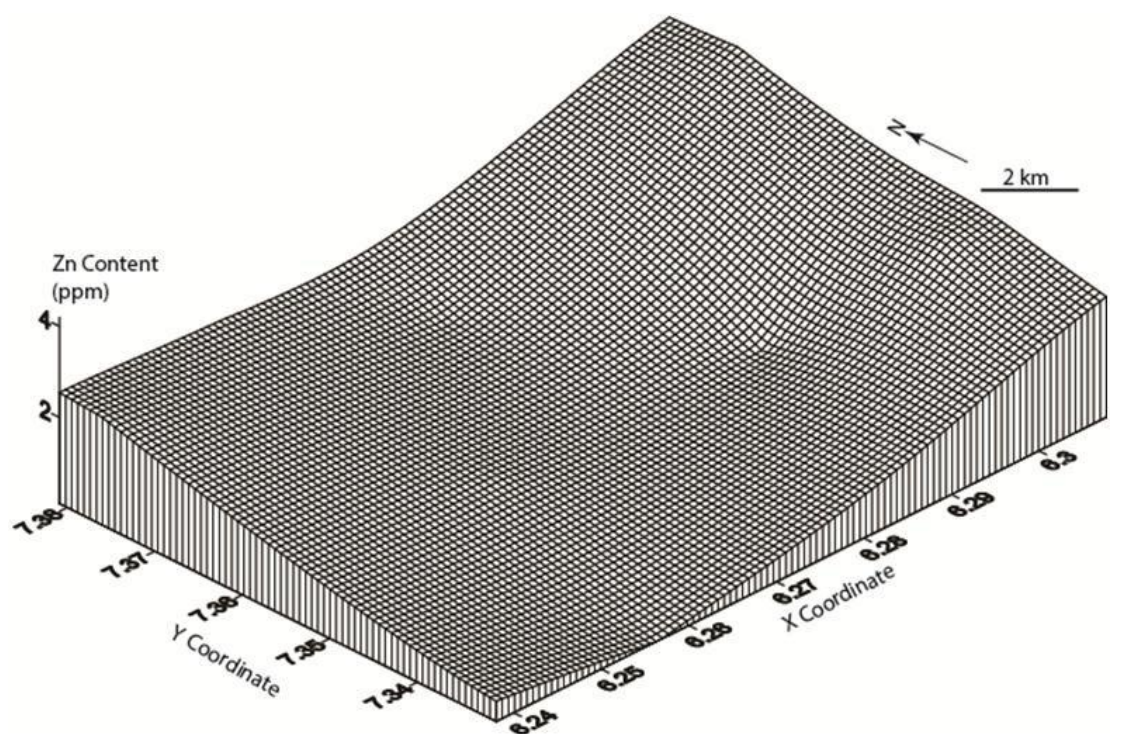

Fig. 5d - 3-D Wireframe map showing the surface variation of $\mathrm{Zn}$ content in stream sediments. The height of the surface illustrates a general metal content that decreases to the northwest.

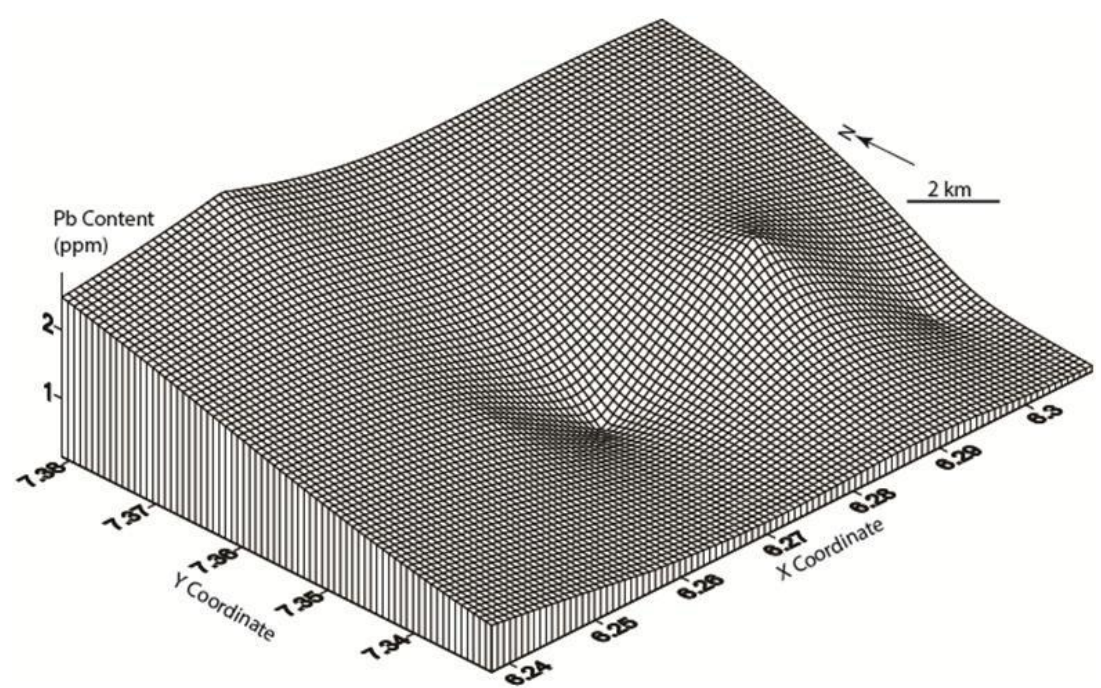

Fig. 5e - 3-D Wireframe map showing the surface variation of $\mathrm{Pb}$ content in stream sediments. The height of the surface illustrates a general metal content that decreases to the north. 


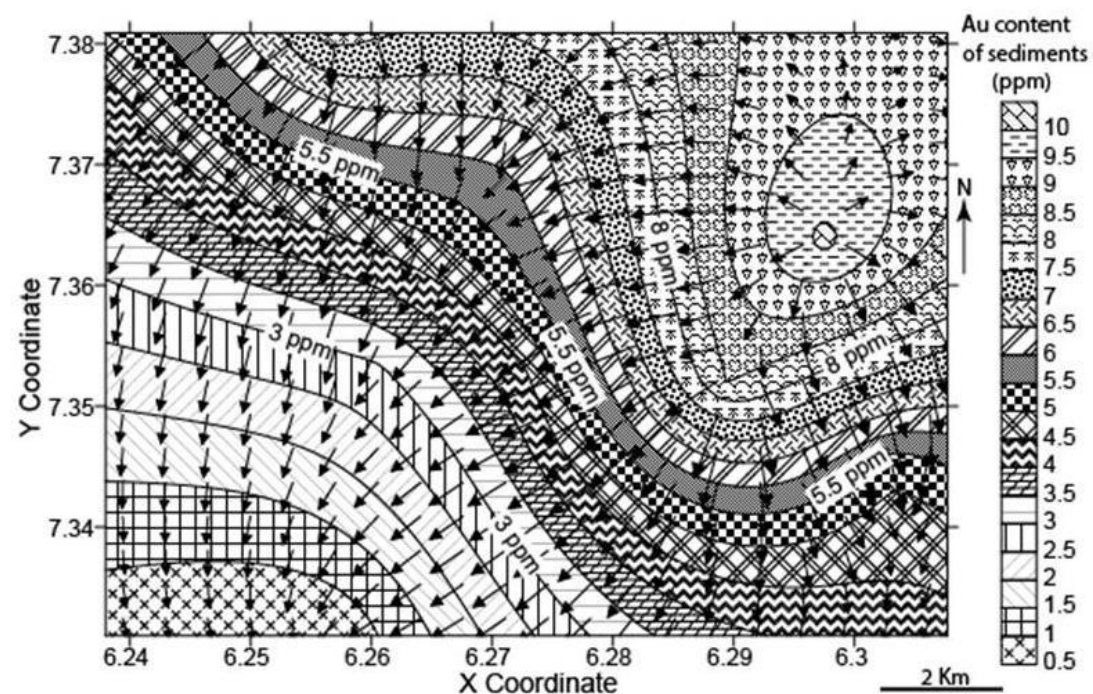

Fig. 6a - Grid vector map superimposed on a filled contour map showing Au dispersion trend.

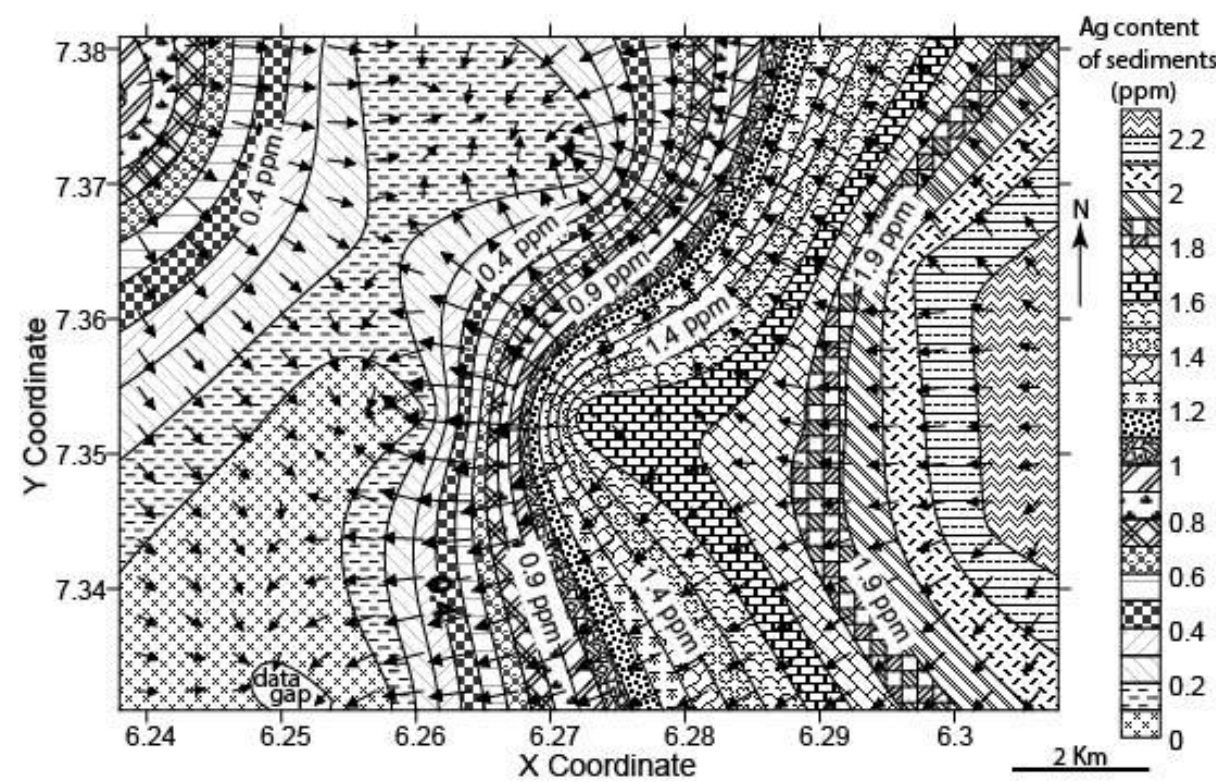

Fig. 6b - Grid vector map superimposed on a filled contour map showing Ag dispersion trend.

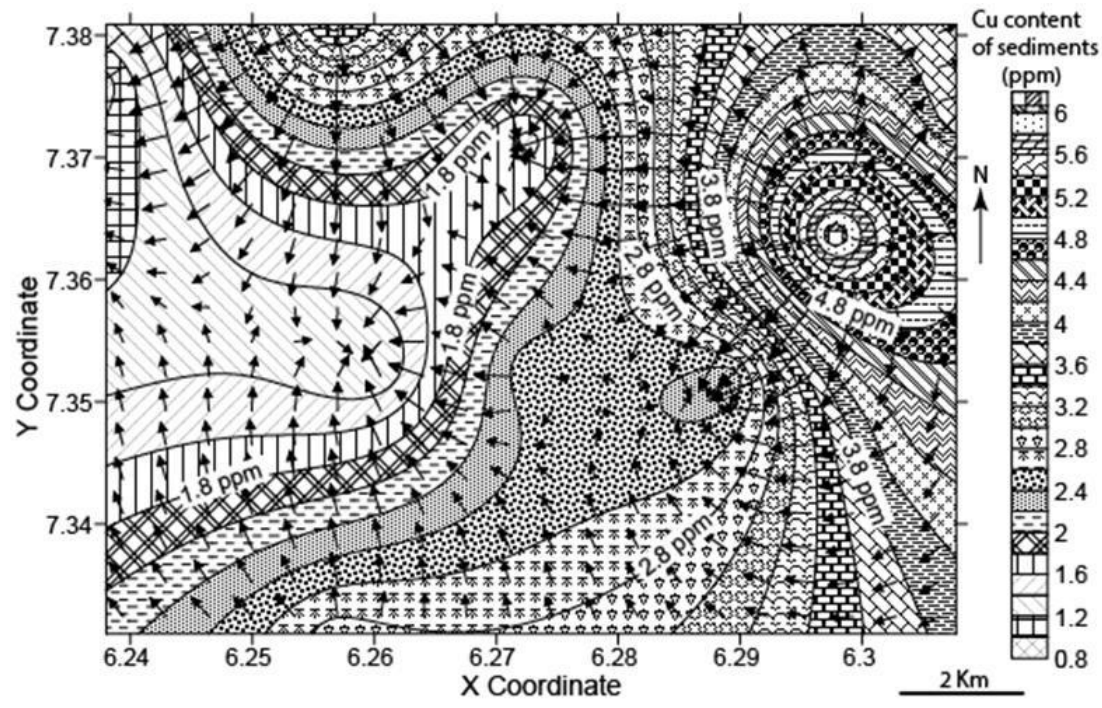

Fig. 6c - Grid vector map superimposed on a filled contour map showing $\mathrm{Cu}$ dispersion trend. 


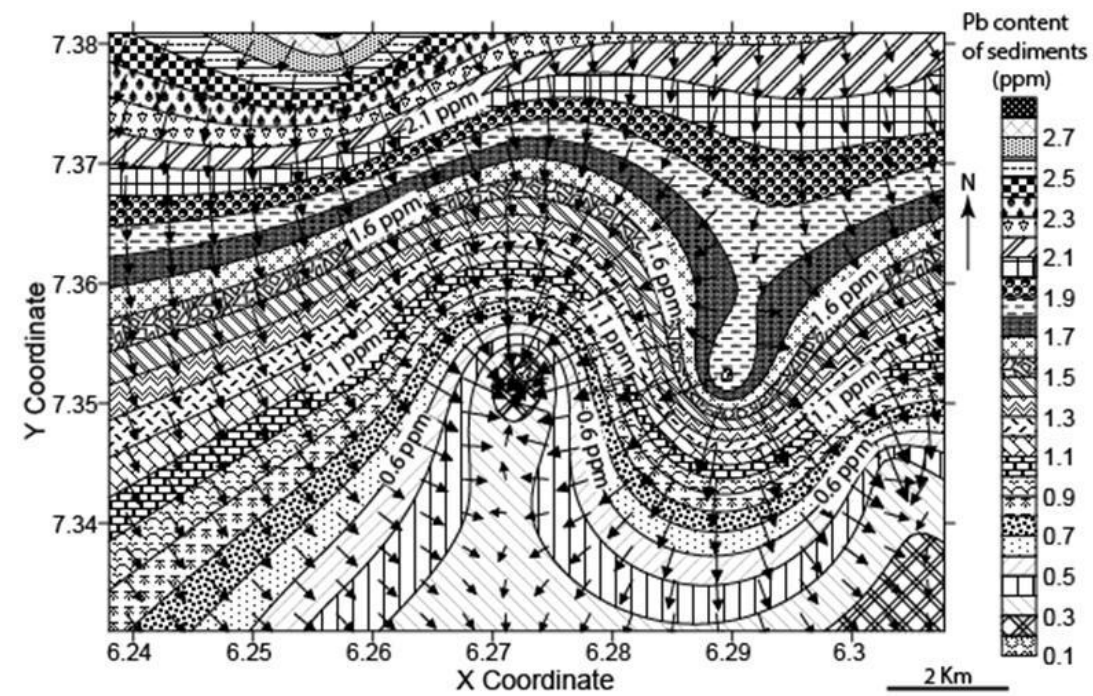

Fig. 6d - Grid vector map superimposed on a filled contour map showing $\mathrm{Pb}$ dispersion trend.

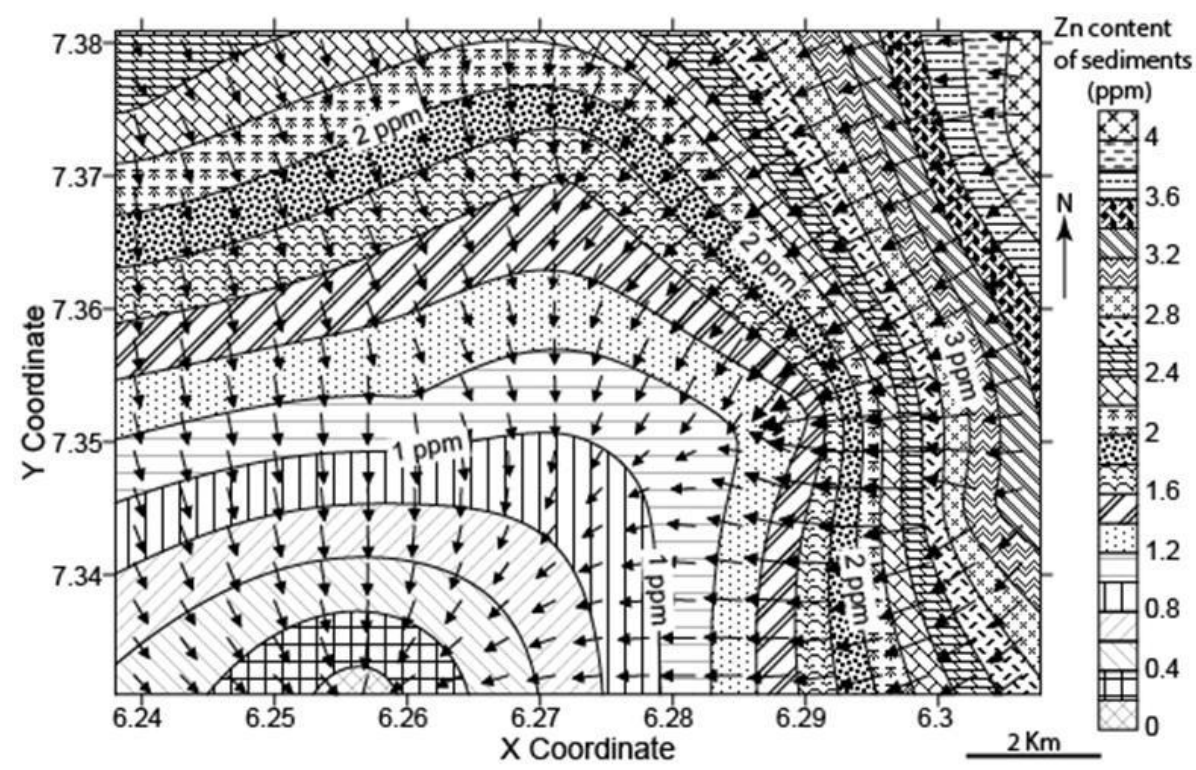

Fig. 6e - Grid vector map superimposed on a filled contour map showing $\mathrm{Zn}$ dispersion trend. 